\title{
The relationship between iron consumption and economic development
}

\author{
GU Xiaowei ${ }^{1, a}$, HUANG Xiaohong ${ }^{1, a *}$, WANG Qing ${ }^{1, \mathrm{c}}$, WANG Fengbo ${ }^{2, \mathrm{~d}}$
}

${ }^{1}$ College of Resource and Civil Engineering, Northeastern University, Shenyang 110004, China

${ }^{2}$ Municipal Propaganda Department of Shenyang 110014, China

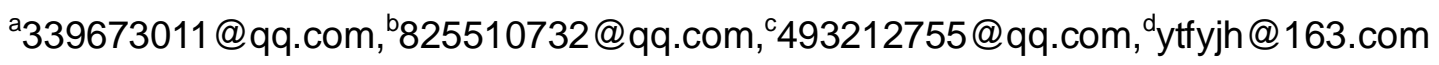

Keywords $\square$ iron ore demand $\square$ intensity of use $\square$ economic structure $\square$ industrial structure

Abstract. This article focuses on the subject of iron ore. Though analyzing the relationship between iron ore consumption and economic development about China and American, it is found that the per capita consumption of iron ore in China was too early, which is not conducive to economic development. Through elaborating the relationship between the consumption and the industrial structure of iron ore, it is revealed that China's industrial structure changes with iron ore consumption intensity and China's economic growth is realized at an excessively high cost of resources.

\section{Introduction}

Mineral resources is one of the basic sources of human production and subsistence, it is an essential part of social and economic development. Experts and scholars had done lots of researches in the relationship between mineral resource consumption and the economy. Yiyun Liu analyzed the relationship between energy consumption and economic development of Shanghai in 2009, the excessive growth of energy consumption and energy inefficiencies will hinder social and economic sustainable development ${ }^{[1]}$. Jingsheng Zhang analyzed China's current situation of iron ore resource exploitation and trend of development in 2007, the development and utilization of iron ore resources is an important guarantee for the sustainable development of China's steel industry ${ }^{[2]}$. Zheng Xin pointed out that energy is one of the important input factors of economic growth after studying the relationship between consumption and economic growth in our country in $2008^{[3]}$.

Form the published literatures domestic, it is found that the study of specific mineral resources is relatively rare, especially the research of economic development of iron ore. This paper focuses on the relationship between iron ore consumption and economic development. To find out the relationship between consumption and economic development. It is necessary to compare our country with the United States in the relationship between the iron ore consumption, and analysis the relationship between iron ore consumption and industrial structure in our country.

\section{Research between ore consumption and economic growth}

Economic development does not only mean the economic scale, but also means to promote the quality of economic and social life. In this paper, elements of economic development include economic growth and structural changes.

Characteristics of Chinese iron ore consumption and economic growth. Since from Reform and Opening, as one of the pillar industries ,iron and steel industry promoted the economy towards industrialization and modernization. Then analyzed the variation characteristics of iron ore consumption in the industrialization process through historical data of our country. Figure 1 is a chart, which revealed China's total consumption of iron ore and GDP comparison from 1978 to 
2011 ,GDP data was taken by United Nations Statistics and based on constant prices in 2005.

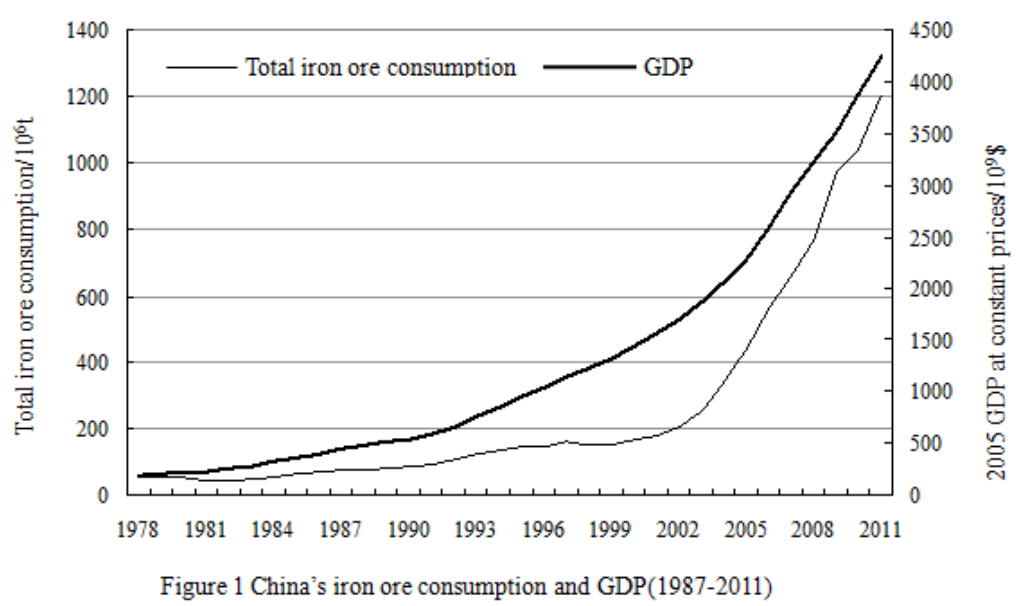

As can be seen from Figure 1, Since the reform and opening up, the economy in China has been developing rapidly, so does the demand for iron ore .Form 1978 to 2011, average annual growth rate of GDP is $9.89 \%$ and an average annual growth rate of consumption of iron ore is $9.86 \%$, in other words, iron ore consumption speeded with economy growth on the overall in this period. The trend graph of iron ore consumption per capita and the GDP per capita is the same as in Figure 1.

Characteristics of American iron ore consumption and economic growth. More than a century of iron ore consumption statistics was found in American industrial sectors, the statistics can reflect the features of iron ore consumption in the process of industrialization and post-industrial era comprehensively. According to time-series data of US consumption of iron ore, it is easy to analysis phase relationship between consumption and economic development. Figure 2 shows comparison between American total iron ore consumption and GDP from1900 to 2011.

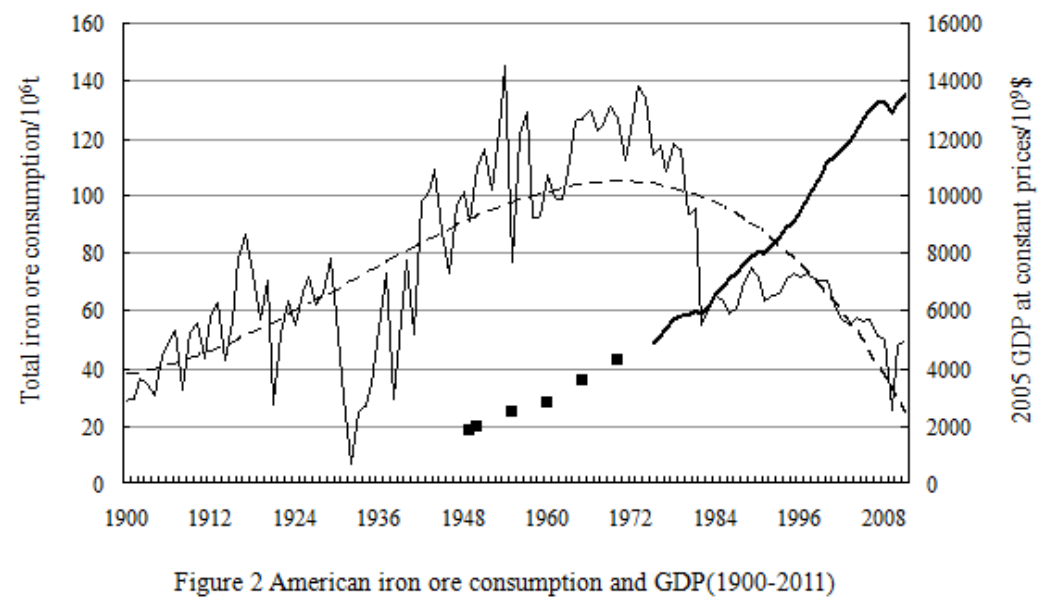

As we can see from figure 2, when America is plunged into depression, two world wars and several crises. the general tendency of GDP growth is relatively stable, except that the growth rate slowed down and decreased at several times. Before the mid-fifties, iron ore consumption and GDP appeared increasing tendency and shows positive correlation. the general trend in iron ore consumption is stable shock and the general trend of GDP is increasing. From early 1950s to 1970s, the general trend of iron ore consumption is relative stable except several vibration, while GDP keep an ascending trend. So the relationship between American economic development and iron ore consumption is absolute decoupled. After the early seventies, the general trend in iron ore 
consumption is clearly down in vibration, while GDP still keep an ascending trend. The phenomenon shows that the decoupled relationship between American economic development and iron ore consumption becoming apparent and stable. The general trend of the United States per capita consumption of iron ore and GDP per capita is similar to figure2.

Comparison between Chinese and American iron ore consumption. Reform and opening up ,China's Per capita consumption of iron ore is only about 1/6 of the United States in 1900. In the 30 years of reform and opening-up, with the rapid development of industrialization and urbanization in our country, per capita consumption of iron ore enters the rapid growth phase. However, with the maturity and declined of industrialization, there is a gradual decline in the United States Per capita consumption of iron ore .

In the study of the relationship between economic development and resource consumption, we often define each unit of economic output of resource consumption as resources "consumption intensity" in the economic system. Here we defined the iron ore consumption per unit of GDP as "iron ore consumption intensity" in economic system. Relations between our iron ore consumption intensity and GDP per capita is different from US both in quantity and in tendency. In quantity, the highest intensity of iron ore consumption is the United States 5 times more; Iron ore consumption intensity is about 65 to 70 times morn than the United States in recent years. On the trend, before the per capita GDP reached \$1,300 to $\$ 1400$, iron ore consumption represented significantly fluctuate declining, which have an adverse effect to the growth rate of per capita consumption of iron ore. After the per capita GDP reached $\$ 1,300$ to $\$ 1400$, iron ore consumption intensity increased at an alarming rate. Besides, coupled with the rapid growth of per capita GDP, it caused the hyper-growth of iron ore per capita consumption in sector. All phenomena shows that China's economy has undergone major changes.

\section{Relationship between iron ore consumption and industrial structure}

The differences between per capita consumption of iron ore and iron ore consumption per unit of output in the same economies, as well as differences in the economies in the same stage of development is mainly determined by the industrial structure. Therefore, it is important to analysis the relationship between iron ore consumption and industrial structure in terms of the study of the relations between iron ore consumption and economic development .

Total iron ore consumption and three-sector value-added. All iron ore used in industrial production processes. Therefore, the scale and rate of development determined in a large degree total iron ore consumption and its growth rate. From found data, there is a strong positive correlation between the consumption of iron ore and the second and third industries value-added. According to the characteristics about iron ore consumption along with time, it is easy to find that iron ore consumption and secondary industry value-added has a high correlation coefficient. Besides, the high correlation coefficient shows that the growth of secondary and tertiary industries is strong driving force for iron ore consumption. However, two major industries demand for iron ore is different: the majority of the secondary industry require inputs of steel or steel products, therefore, growth in the secondary industry is direct driving force for iron ore demand in some degree. However, three-sector industry formed indirect driving force for iron ore demand by purchasing a part of the second industry of iron and steel products (including equipment), We can't consider two industries having the same level of driver just because the correlation coefficient between the amount of iron ore consumption and two major industries is almost equal.

Iron ore consumption intensity and the proportion of three industries. Another general knowledge of iron ore consumption is that the more the proportion of secondary industry in the whole 
economy is, the higher its iron consumption intensity is. This qualitative relationship for big stages of economic development is applicable and the current iron ore consumption is much higher than the strength of the United States. China and the US economy are at different stages in economic development--Our country is at the stage of advancing the industrialization rapidly, the United States enter the post-industry era. Significant differences in economic structure has led to a huge iron ore consumption intensity difference.

Starting from 1985, the proportion of secondary industry in the whole economy is increasing, but changes of iron ore consumption intensity is very different, experienced a rapid decline from 1978 to 1982, the basic stability from 1982 to 1994, the rapid decline from 1994 to 2001 and rapid rise after 2001. Although after 1985, iron ore consumption intensity decreased substantially, which corresponds to the proportion of secondary industry remained basically stable or increased slightly, the contact between the two is not obvious. To explain " $U$ " shape characteristics of iron ore consumption intensity changes from Since reform and opening, especially in the turn of the century turning point, it requires to analyze the internal structure of industry in-depth.

\section{Conclusion}

Iron ore consumption and the level of economic development have stage relations. From cross-sectional data in 2011, it shows that iron ore consumption intensity dropped first and then rises, but kept stable in the end. High-income countries which per capita GDP (2005 constant prices) is higher than $\$ 25,000$, the strength of iron ore consumption is lower than world average. At the macro level, secondary industry and the rapid growth of capital formation in China's economy and their high proportion of GDP is the source power for driving the rapid growth (especially into the 21st century, high-speed growth).

\section{Acknowledgements}

The authors would like to acknowledge the Natural Science Foundation of China(Grant No. 51474049),Liaoning Natural Science Foundation of China(Grant No.2014020040, 2012010064-401), Fundamental Research Project of Liaoning key laboratories (Grant No.LZ2014020), Shenyang Science and Technology Plan Project(Grant No.F14-231-1-07), Doctoral Tutor Founding of Ministry ofEducation(Grant No.20130042110012), Liaoning Province's Hundred, Thousand and Ten-Thousand Talented People Program(2012921075), for their financial supports in the course of the research work presented in this paper.

\section{References}

[1] Yiyun Liu. Consumption and economic development in Shanghai energy[D]. Fudan University,2009.

[2] Jingsheng Zhang. Iron ore resources development and utilization and development trend[J]. China Metallurgical,2007,42(2):10-12.

[3] Zheng Xin. Study on the relationship between energy consumption and economic growth in our country[D]. Capital University of Economics, 2008:5-13.

[4] Xinchuang Li. Thoughts on the development of iron ore[J]. China Mining,1996,5(23):2-3.

[5] J.S. What is the prospect of the North American iron ore industry[J].North American Metal Mines2002,(2):1.

[6] Zhenlin Fan. Chinese iron ore resources in the supply and demand situation analysis[D]. Chinese Geology University,2009:17-43. 
